\title{
Evaluation of a Turbocharger Turbine Wheel
}

\author{
J.L. McDougall *, R.R. Knuteson *, M.E. Stevenson *, and F. E. Schmidt, Jr. ** \\ * Engineering Systems Inc., 6230 Regency Parkway, Norcross, GA 30071 \\ ** Engineering Systems Inc., 4215 Campus Drive, Aurora, IL 60504
}

A twin turbocharged single-engine six-passenger aircraft experienced a drop in manifold pressure followed by a loss of oil pressure while in cruise flight. Upon engine seizure, a forced landing was made resulting in extensive damage to the aircraft and no casualties. Two different entities concluded that aluminum bearings in the turbocharger were of insufficient hardness and ultimately caused the accident.

Visual examination of one of the turbocharger turbine wheel, revealed evidence of impact damage at the blade tips, a region where contact with the surrounding case would generally not occur. Energy dispersive spectroscopy (EDS) and phase mapping revealed evidence of FOD manifested in the presence of iron and chromium immediately adjacent to the blade damage. Visual examination of the turbine housing inlet revealed evidence of FOD in the form of impact damage on the interior surface. Metallographic evaluation revealed no evidence that the turbocharger turbine wheel was overheated.

In conclusion, a review of the relied upon aluminum bearing hardness data, in conjunction with additional hardness testing, revealed that the aluminum bearings in the subject turbocharger met the manufacturer's specifications. Further examination of the aircraft engine, specifically the turbocharger, revealed evidence of foreign object damage (FOD).

FIG. 1. Optical Micrograph of turbocharger turbine wheel blade damage FIG. 2. Photomicrograph of undamaged turbine blade with no evidence of creep voids

FIG. 3. SEM of metallographically prepared turbocharger blade $(10,000 \mathrm{x})$

FIG. 4. SEM of metallographically prepared turbocharger blade (50,000x)

FIG. 5. SEM micrograph of damaged turbocharger turbine wheel blade (100x)

FIG. 6. Phase map with evidence of foreign material on damaged turbocharger blade (100x)

FIG. 7. SEM micrograph of damaged turbocharger turbine wheel blade (1000x)

FIG. 8. Phase map with evidence of foreign material on damaged turbocharger blade (1000x) 

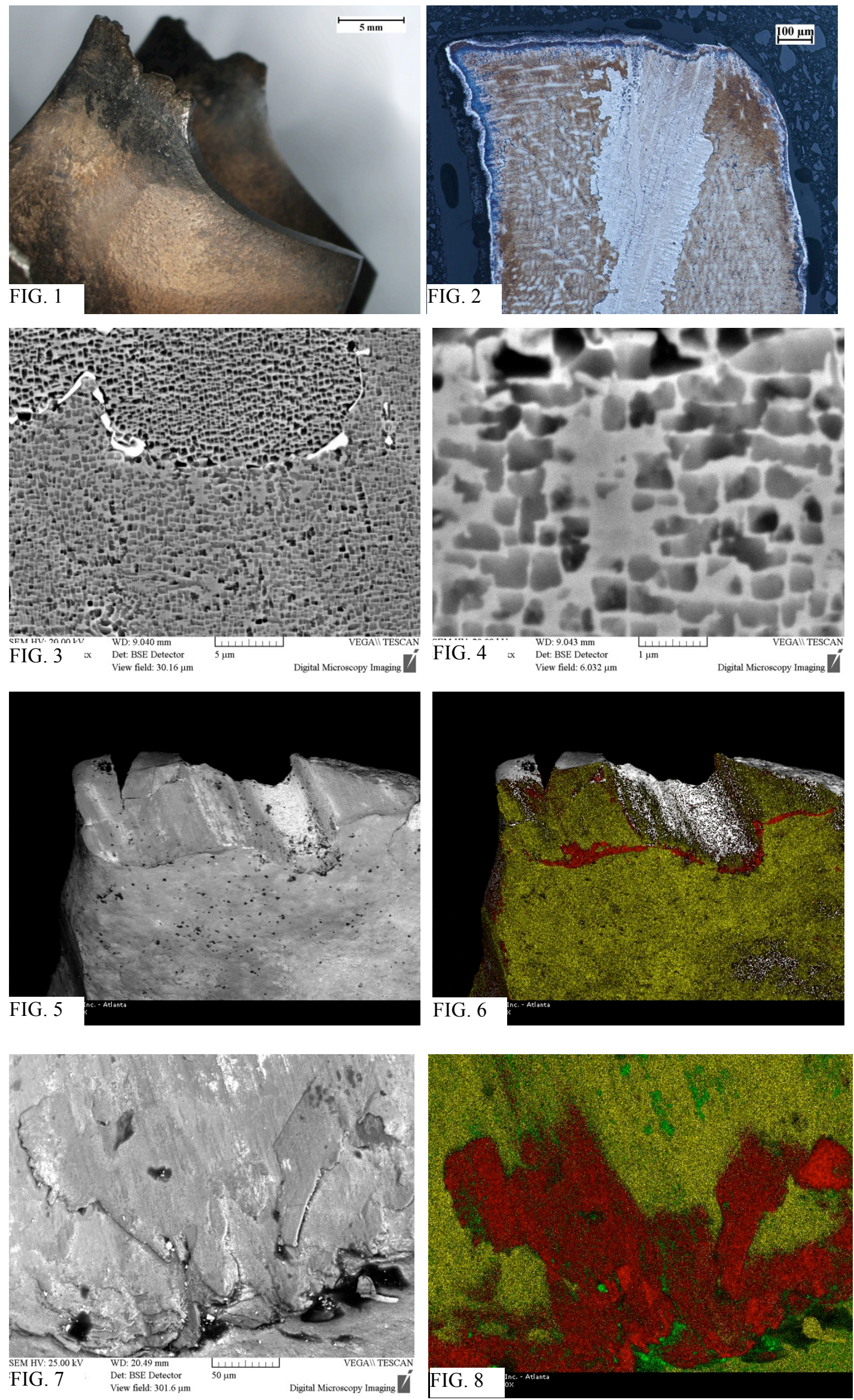